\title{
Energy Efficient Communities - A Collaboration Project of the International Energy Agency IEA
}

\author{
Reinhard Jank ${ }^{1}$ \\ ${ }^{1}$ Volkswohnung GmbH, Karlsruhe, Germany \\ Tel: +49 (0) 7213506 238,E-mail: reinhard.jank@volkswohnung.com
}

\begin{abstract}
Summary: The background and purpose of a project to evaluate international experiences on planning and implementation of "Energy Efficient Communities" is explained. First results are presented, showing approaches and successes/failures on different levels of “communities”, and conclusions to be drawn.
\end{abstract}

Keywords: Urban energy planning, energy system models, IEA ECBCS R\&D projects

\section{Introduction}

Since in general over $40 \%$ of the end energy use in OECD countries is caused by the built environment, an increase of the energy performance in this sector, together with the increased use of renewables for electricity generation, will be the key to a successful energy and climate change policy in the industrialized world. $80 \%$ of our built environment is located in towns and cities. For this reason, it is decisive that cities, small or large, will be able to achieve such ambitious energy goals, and this will entail enormous changes in urban fabric and urban energy use patterns in the future. During recent years, new energy standards like the German "Passivhaus" or the Swiss "Minergie", or even "Net Zero Buildings", have been introduced successfully, which have facilitated a reduction of end energy consumption by a factor of 2 or more compared to conventional new buildings. Is this the solution of the problem? Looking at the existing buildings in our cities and considering the fact, that some $80 \%$ of them will still be there in 2050, and their current primary energy consumption for heating, cooling, hot water and electric appliances is in most cases beyond $300 \mathrm{kWh} \mathrm{PE}_{\mathrm{PE}} / \mathrm{m}^{2}$, a reduction by $80 \%$ would require a primary energy use level of about $60 \mathrm{kWh} / \mathrm{h}^{2}$. While this is technically feasible with today's technologies, there are economic limits due to a non-linear increase of costs. To reduce the economic burden, cost-efficient alternatives must be found to simply decreasing Uvalues below economic limits.

Due to economies of scale, a number of technologies, like cogeneration or combined heat and power, waste heat recovery, biomass, geothermal energy, solar heating (and cooling), and others, are more efficient - in technical and economic terms - when used in large installations instead of small ones. Taking advantage of these technologies where locally available will enable the primary energy consumption (or GHG emissions) achieved by an optimized system to fall possibly to the best available standards (in terms of $\mathrm{kWh} / \mathrm{m}^{2}$ or $\mathrm{kg} \mathrm{CO} / \mathrm{m}^{2}$ ) for new buildings, but with lower cost and with the advantage of a feasibility at community scales. A successful urban climate change policy will only be available if such options can be found and realized; otherwise, it will just be too expensive. Therefore, communities will have an essential role to play in the future to make this happen.

As the number of cities with successful climate change policy is still very low, it is obvious that there are powerful barriers that prevent cities from recognizing and implementing their potentials. A strategy to bypass these barriers is needed, in the form of integrated energy planning for neighbourhoods or energy master plans for whole cities - and the corresponding implementation strategies. Contrary to individual pilot or demonstration buildings, the aim of community-wide energy concepts must be to find an optimized solution in economic terms rather than introducing cutting-edge technical innovations, otherwise implementation would 
not be achievable. This makes a big difference between community projects and projects that are involved just with one single building. This has been recognized in several countries, where national programs for urban energy planning projects have been initiated. To benefit from experiences made by those national Case Studies, an international project (an "Annex") was commenced within the framework of IEA's "Energy Conservation in Buildings and Communities" Implementing Agreement. The title of this ECBCS-Annex 51 is "Guidelines and Case Studies for Energy Efficient Communities". The work has begun in 2009 and will be finished until autumn 2012. 11 countries participate in this Annex.

\section{Objectives and Project Structure}

In Local or Urban Energy Planning, there are no standard solutions. An optimized design and implementation strategy must be found in every new case. The subject of Annex 51 is to identify methods how to find such solutions and to provide successful examples: Its aim is to provide stakeholders in communities with the necessary information to be able to achieve their local climate policy goals more successfully than in the past. This objective has defined the work plan of Annex 51:

- explore the state-of-the-art of local energy planning with respect to methods, tools and strategies: Subtask A

- exchange experiences from projects (“Case Studies”) carried out within the ongoing national "city” programs: Subtask B for neighborhoods and Subtask $C$ for whole cities

- summarize the outcome of this work in the form of a guidebook that serves as a source of methodological knowledge and practical examples for local decision makers and planners, and supply a simplified planning tool for decision makers to be used in the early planning phase: Subtask D

\section{Annex 51 - Subtasks}

\subsection{Subtask A: Review on Existing Planning Tools and Implementation Strategies}

Subtask A will be finished until summer 2011. The Subtask leader is France, represented by P. Girault and A. Koch from EiFER - European Institute for Energy Research (a research subsidiary of EdF in Karlsruhe). In this Subtask, selected successful Local or Urban Energy Planning projects (“LEP” or "UEP”) from the participating countries, and planning methods and tools used in practice are evaluated, but more importantly, implementation strategies and instruments are discussed and conclusions will be drawn.

\subsubsection{LEP - Neighbourhood Scale Projects}

The LEP projects showed a large variety in terms of size, uses, targets, building constructions and energy systems involved, such as inner city revitalisation projects, as Western Harbour in Malmö or Regent Park, Toronto, or a commercial downtown district in Yokohama, until greenfield residential developments like Burgholzhof in Stuttgart. The number of residents or users is between 1.000 and 10.000 in most cases. While most of the cases have been finished, others are still in some stage of implementation.

The technical descriptions of the LEP projects presented in Subtask A have a big value in itself, because they show the large variety of solutions and approaches that can be used to achieve the energy or GHG goals strived for in the different projects. Due to the fact that in most cases there was no direct access to detailed data in Subtask A (planning data, measured data after completion, cost and price structures etc.), a quantitative evaluation is impossible for the Subtask A cases. In particular, it was not possible in most of the projects to compare 
the initial targets in terms of energy efficiency or GHG reduction with the reality after project completion. This should be different in Subtasks B and C, because the respective reviewers in most cases are directly involved with the Case Studies considered there. Conclusions to be drawn from Subtask A in terms of planning and implementation processes of LEP projects, show that five major influences seem to be common as success factors:

- a decision maker being directly involved in the specific project and acting as a driver in terms of technical innovations, energy / sustainability targets, feed-back to stakeholders etc.

- bilateral/personal information transfer from comparable other community projects that have been successfully implemented

- a "contract" at the initial phase of the project that is signed by all involved actors in mutual agreement and where the main targets of the LEP project are laid down

- the perspective of grants or allowances for the project according to some public funding program (whereas the absolute amount of money received seems to be less important)

- an "integrated approach", aiming at a holistic view of the long-term perspective of the neighbourhood or district under consideration in terms of the three components of "sustainability": social, economic and ecologic development.

In every specific LEP project, there might be other important issues that need proper solutions, but if all these five favourable points as mentioned above are valid in a project, the perspectives for successful implementation seem in general to be good.

\subsubsection{UEP - City Scale Projects}

A detailed discussion of the conditions and approaches of city Case Studies in terms of energy or GHG policy is being done in Subtask C. In Subtask A, only 2 cities have been presented as cases, Lyon in France, and Freiburg in Germany. While Lyon has began only recently with the establishment of a "climate plan", in the City of Freiburg a continuous municipal energy policy has taken place since almost 30 years. Four phases can be identified: an initial period of political dispute (1980ies), a phase of first quantification of urban energy saving and renewable potentials and targets (1990 - 1996), a learning phase of practical implementation (until 2003) and a phase of re-adjustment to ensure successful achievement of the energy targets (until 2007). These last two phases may repeat periodically during implementation. The following chart presents wishful and real GHG developments in Freiburg over 20 years of time, showing that successful GHG policies for whole cities need a very long time and continuous adjustments to make sure that there is a move towards the targets set.

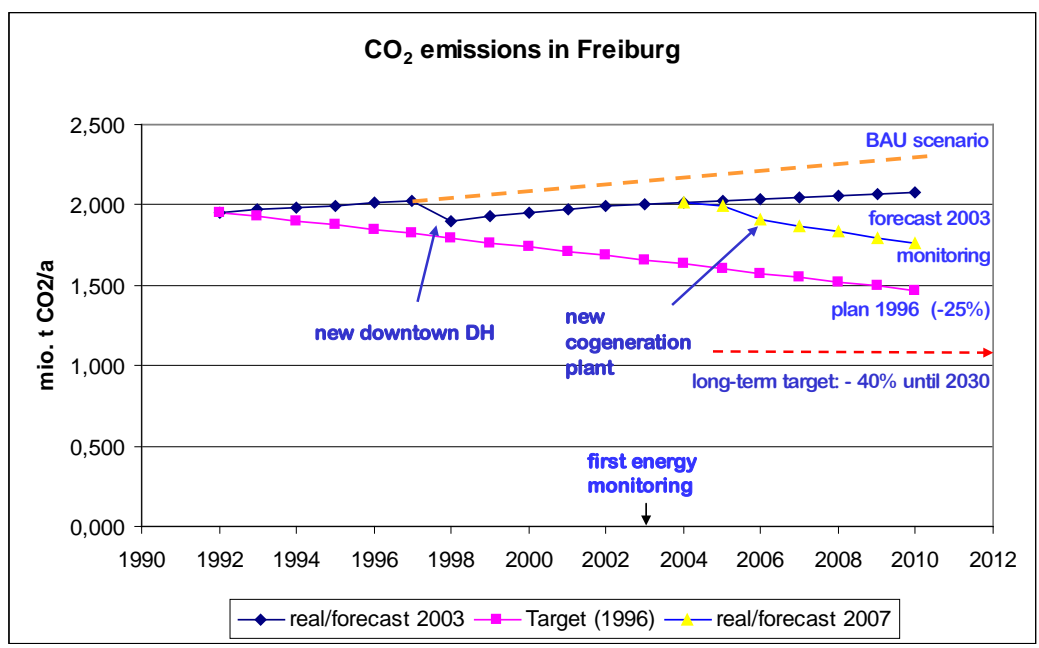

Fig. 1: Projected and real development of $\mathrm{CO}_{2}$-emissions in Freiburg1992 - 2010 
Fig. 1 illustrates the results of these phases in terms of urban GHG emissions in Freiburg, beginning with the first quantification phase in 1995. Based on this, a target of minus $25 \%$ $\mathrm{CO}_{2}$-emissions until 2010 (compared to 1992) was decided in 1996 by the City Council, while focusing its policy to solar energy and on ambitious standards for new buildings.

When a first evaluation of this policy, made in 2003, proved that the target until 2010 would be clearly missed, a new phase of analysis of more detailed and realistic energy scenarios was initiated. A first conclusion taken was that it would be necessary to track periodically the effects of measures made in the framework of the municipal energy policy. For that purpose, a tailor-made municipal energy and GHG balancing scheme was developed. However, developing a successful implementation policy based on local energy conservation and renewables potentials was a difficult step, which needed extensive discussions. To enable a detailed discussion of different policies, a spread sheet model with four "scenarios" was developed, which was used to quantify different assumptions or combinations of measures over a given timeline. As a result, in 2008 an almost unanimous decision was taken by the City Council to define a new GHG target of "minus $40 \%$ until 2030" compared to 1992. This decision was combined with the presentation of a "climate change roadmap". The municipal administration was appointed to be responsible to report periodically on their implementation.

Most important points on the "climate change roadmap" were the support of a retrofit program of the building stock making use of federal building modernisation pro grams, enforcement of neighbourhood scale district-heating schemes using cogeneration, biomass or biogas, substitution of all remaining coal uses, support of electricity saving programs for private households, and a diversity of measures in the mobility sector. Eventually, an ambitious modernization program of the municipal buildings was decided to serve as a model also for other investors in the commercial sector.

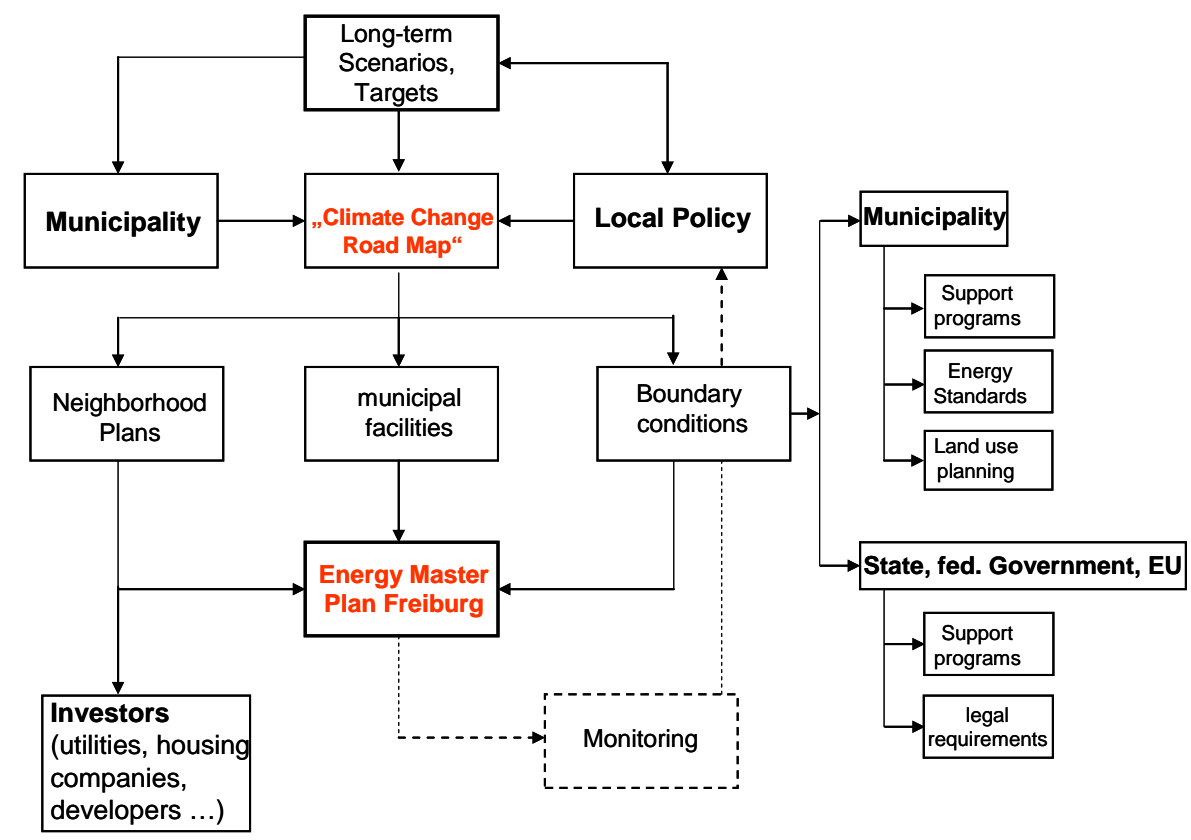

Fig. 2: Climate change policy in Freiburg 2008 - Organisational Structure

Fig. 2 shows a sketch of the decision making structure that can be outlined. The experiences in Freiburg have shown that the pre-requisites of a successful municipal energy and GHG policy will consist of a 
- detailed information base on local potentials and options

- realistic target-setting based on achievable results

- detailed delegation of responsibilities and obligations

- continuous monitoring and communication

- installation of a project management (authority, energy agency, ...) responsible for work organisation, reporting and feed-back to involved stakeholders.

As can be learned from the experiences in Freiburg, the definition and implementation of a community energy policy is a task, which requires a certain continuity in know-how and management capacities over many years of time. If successful, it will contribute to local economic development and quality of life as well.

\subsubsection{Methods and Tools}

On the scale of neighbourhoods or cities, different questions are to be answered by the planner compared to the scale of one individual building. While a number of building planning tools are available, which have proved their practicability to achieve useful results - examples are the "Passivhaus Planning Package" (PHPP) in Germany, or eQuest in the US, HOT3000 in Canada, Enorm in Sweden etc. - for neighbourhoods or districts, the situation is different. It was one purpose during Subtask A Case Study evaluation to explore, which planning methods and tools are currently in use (or in demand). On the scale of neighbourhoods or districts, the question of energy (and GHG) balances for demand and supply, annual and diurnal variations, economic optimization of both supply and demand measures are relevant for the planner. To be able to include a consideration of energy distribution, an interface with GIS would be useful, such as an energy map. However, on this scale, commercial energy models are not really available so far. Planners often use several different self-made calculation tools, with the disadvantage of intransparent calculation methods and lack of interfaces to existing data bases. As a result, every LEP project is a singular project. However, the situation with energy modelling of neighbourhoods (or cities) is better than currently apparent in planning practice, since several energy system models are "there" and used by academic experts in projects which have often the character of research projects. Two "models" are currently in widespread use, at least in Germany, Austria and Switzerland, one of them "GEMIS", which is used most often as a reference database for primary energy and GHG factors for a wide range of energy systems, but is also capable to be used to "model" energy systems, including default cost values [2] and the other "model" is ECORegion, a tool primarily intended to make up energy and GHG balances of cities [3]. Two additional balancing tools, BilanCarbon of ADEME (France) and "Energy Balance" in Denmark have been used in Subtask A Case Studies, as well as pure simulation tools of energy supply systems, such as GOMBIS or EISAB, that are applied in Subtask B Case Studies (Germany, Japan) and will be evaluated there. Comprehensive energy system models, such as TIMES, POLIS or PERSEUS, are powerful, but complex optimization models that need skilled users and are in general not used by conventional planners (one application of POLIS is presented in [8]). It would be an important task of the future to develop such tools in a way that they can be used also beyond academic circles of model developers. One different approach has been developed by [4], where a physical model (buildings, spaces between the buildings, orography; climate) is blended with GIS and scanning data to simulate the annual energetic development of a whole neighbourhood including thermal energy demand, solar gains and energy system components and (statistical) user behaviour.

A simplified energy benchmarking approach for neighbourhoods was discussed in Case Studies in Germany [5]. Here, the idea was to extend the existing methods of building energy per- 
formance rating, where the specific thermal energy demand of a building, $\mathrm{q}_{\mathrm{H}}+\mathrm{q}_{\mathrm{W}}\left(\mathrm{q}_{\mathrm{H}}=\right.$ space heating demand, $\mathrm{q}_{\mathrm{W}}=\mathrm{DHW}$ demand, both in $\left.\mathrm{kWh}_{\mathrm{th}} /\left(\mathrm{m}^{2} \cdot \mathrm{a}\right)\right)$, is covered by an energy system with an end energy use ratio $e_{\mathrm{EE}}\left(\mathrm{kWh}_{\mathrm{EE}} / \mathrm{kWh}_{\mathrm{th}}\right)$. The term $\mathrm{p}=\left(\mathrm{q}_{\mathrm{H}}+\mathrm{q}_{\mathrm{W}}\right) \cdot \mathrm{e}_{\mathrm{EE}}$ $\left(\mathrm{kWh} \mathrm{EE}_{\mathrm{E}} /\left(\mathrm{m}^{2} \cdot \mathrm{a}\right)\right.$ is used for the energy performance rating of the building.

Looking at a neighbourhood, typical uses (residential building types, others) have to be identified and the term $\mathrm{p}=\left(\mathrm{q}_{\mathrm{H}}+\mathrm{q}_{\mathrm{W}}\right) \cdot \mathrm{e}_{\mathrm{EE}}$ as mentioned before has to be weighted according to the use areas to calculate an average value of $p$ for the neighbourhood. At this scale, also the quality of the end energy delivered to the neighbourhood has to be considered. This can be thermal energy from a central heating plant, using a biomass boiler in the base load, or a cogeneration plant, a geothermal heat pump, waste heat utilization etc. In every of these cases, the "quality" of the end energy supply process, characterized by $f_{\mathrm{EE}}\left(\mathrm{kWh} \mathrm{h}_{\mathrm{PE}} / \mathrm{kWh} \mathrm{h}_{\mathrm{EE}}\right)$, can be described by an appropriate formula. For a central heating station for instance, operated with wood chips in base load and with a gas peak boiler, one may be interested in the "quality" of the end energy supply provided via a neighbourhood heating scheme in terms of fossil energy consumed $\left(\mathrm{kWh}\right.$ foss $\left./ \mathrm{kWh}_{\text {th }}\right)$. In this case, $\mathrm{f}_{\mathrm{EE}}$ is given by $\mathrm{f}_{\mathrm{EE}}=\left(1-\mathrm{f}_{\text {ren }}\right)$, where $\mathrm{f}_{\text {ren }}$ is the fraction of renewable energy used in the central station (for instance, $f_{\text {ren }}=0,80$ ). The resulting energy performance factor $\mathrm{p}\left(\mathrm{kWh}_{\mathrm{PE}} /\left(\mathrm{m}^{2} \cdot \mathrm{a}\right)\right)$ of the neighbourhood is then given by

$$
p=\left(q_{H}+q_{W}\right) \cdot e_{E E} \cdot f_{E E}=\left(q_{H}+q_{W}\right) \cdot e_{E E} \cdot\left(1-f_{\text {ren }}\right)
$$

In the case of a cogeneration plant instead of the wood-chip boiler, $\mathrm{f}_{\mathrm{EE}}\left(\mathrm{kWh} \mathrm{hE}_{\mathrm{PE}} / \mathrm{kWh}_{\mathrm{th}}\right)$ would be calculated from

$$
f_{E E}=\frac{1+s}{\eta_{B}}-\frac{s}{\eta_{e l}}
$$

with

s ... ratio of electric to thermal output of the cogeneration plant $\left(\mathrm{kWh}_{\mathrm{el}} / \mathrm{kWh}_{\mathrm{th}}\right)$

$\eta_{\mathrm{B}} \ldots$ overall efficiency of the cogeneration system $\left(\mathrm{kWh}_{\mathrm{EE}} / \mathrm{kWh}_{\mathrm{PE}}\right)$

$\eta_{\mathrm{el}} \ldots \quad$ average electric efficiency of the regional power plant mix. ${ }^{1}$

In other cases, such as a heat pump for instance, different formulae for $\mathrm{f}_{\mathrm{EE}}$ would have to be used.

One task of Annex 51 is to evaluate the current situation of planning tools and their practical use (or development needs). The basic requirements for such a tool to be applied for LEP projects would be

- description of energy demands (hourly, monthly, annually) and supply systems and their future developments at neighbourhood scale

- balances in terms of costs and GHG on neighbourhood level

- scenario building (business as usual as reference and scenarios using different technical options) for neighbourhoods and cities

- costs and economic assessment (e.g. using LCA) as basis for economic optimization

- continuous monitoring of implementation.

\footnotetext{
${ }^{1}$ In real applications, the fact that only the base load will be made from cogeneration, and the existence of losses in heat distribution and electric transmission would have to be considered, which makes the formula more complicated.
} 
It remains to be shown if existing tools can be used by conventional planning consultants, perhaps after adequate re-designing of the user interface, or if there is a need for a completely new planning tool still to be developed.

\subsection{Subtask B: Case Studies on Energy Planning for Neighbourhoods}

This is a continuation of the work carried out in Subtask A, with the difference that in Subtask $\mathrm{B}$ the focus is on recent or ongoing Case Studies with explicitly innovative character, be it technically, methodically or with respect to the implementation approach. 14 Case Studies in 11 countries are evaluated, which cover existing neighbourhoods as well as new ones, and residential as well as mixed use neighbourhoods. Another difference to Subtask A is that the Case Study reviewers here are in most cases directly involved and therefore have access to detailed information as to cost structures and prices, business models or implementation strategies. This will allow for a much more detailed evaluation compared to Subtask A. This work is ongoing, led by the University of Linköping (Prof. B. Moshfegh, Prof. H. Zinko). Three of the Subtask B Case Studies are being presented at the WRE Conference [6-8].

\subsection{Subtask C: Energy and Climate Change Strategies for Cities and their Implementation}

With respect to international long-term energy and climate change targets, successful urban climate change policy is a key to success: without massive GHG mitigation in all cities, climate change targets can not be achieved. Compared to neighbourhoods, climate change strategies on city scale are much more complex and need much more time. Ongoing initiatives, such as the International Climate Alliance, ICLEI or the C 40 Initiative have been formed in the past, and more recently the EU-based "Covenant of Mayors", to support members of their organisations in the development of urban climate change strategies. However, really successful cities are still the exception rather than the rule.

As in Subtask B, methods and implementing strategies shall be evaluated using successful cities as Case Studies, but still more important is a description of the transition processes that cities have to undergo in terms of organisation and local implementation of their climate change master plan.

The Subtask C Leader is Prof. Kimman from Hogeschool Zuyd in Herleen (NL). Cities that are being evaluated in Subtask C are Tilburg and Apeldoorn (NL), Ludwigsburg (D), Stockholm, Zurich, St. Johann (A) and the City of Prince George (CAN). Results of this Subtask will be available in 2012.

\subsection{Subtask D: Guidebook and Energy Model for Decision Makers}

The main deliverables of Annex 51 for the general public will be provided by this Subtask, containing the essential results and conclusions drawn from the other Subtasks. The intention of the "Guidebook to Successful Urban Energy Planning" is to provide the necessary background of methods and usable planning tools to urban planners and decision makers, to select and explain the most interesting Case Studies of Subtasks B and C, which can serve as good examples for other cities, and to provide to the user a "Pathway on How to make an Urban Climate Change Action Plan and Implement it Successfully”.

\section{Conclusions}

First results and experiences of the work made in Annex 51 have shown that for both Local and Urban Energy Planning, there is a lack in generally acknowledged and practically used 
methods and planning tools as part of the necessary knowledge base of planners and decision makers in municipalities. In addition, there is a need for learning processes from municipalities or cities that have proven to be successful in establishing a local energy and climate change master plan and transition into a successful implementation phase. Through the work being made in Annex 51, both needs shall be satisfied, with the aim to provide to this target groups a practical guidebook that is really beneficial in their every days work.

\section{Acknowledgements}

The author would like to thank all Annex 51 participants (being too large in number to be explicitly mentioned here) for continuous discussions during the course of our common project. In particular, I want to mention my Subtask Leaders, A. Koch and P. Girault from EiFER in Karlsruhe, Prof. B. Moshfegh and H. Zinko from the University of Linköping, Prof. J. Kimman with his assistant, W. Broers, Hogeschool Zuyd in Herleen, and H. Erhorn-Kluttig, Fraunhofer Inst. für Gebäudephysik, Stuttgart. In addition to these, I want to mention Prof. D. Robinson, ETH Lausanne, and Prof. U. Eicker, FH Stuttgart, for valuable discussions on the sometimes cumbersome issue of "energy models". My own contributions would not have been possible without the financial support of the Secretary of Economics and Technology, Germany, which has supported R\&D in energy since decades in general and IEA co-operative projects in particular.

\section{References}

[1] IEA ECBCS Annex 49,', D. Schmidt et al.: Low Exergy Systems for High Performance Buildings and Communities; www.ecbcs.org

[2] U. Fritsche et al.: GEMIS - Globales Emissions-Modell Integrierter Energie-Systeme, Version 4.6 - www.oeko.de/service/gemis/de/indes.htm

[3] EcoSpeed AG, Zurich: ECORegion - Energie- und Treibhausgas-Bilanzierung für Städte; www.ecospeed.ch

[4] D. Robinson et al.: CitySim: Comprehensive Micro-Simulation of Resource Flows for Sustainable Urban Planning, Int. IBPSA Conference on Building Simulation, Glasgow 2009

[5] H. Erhorn-Kluttig et al.: Energetische Quartiersplanung, Fraunhofer IRB Verlag, Stuttgart 2011

[6] B. Boutaud et al.: The Franklin District of Mulhouse: First French Experience of low energy Building Renovation in a historic area of the City Centre, WREC 2011, Linköping

[7] R. Kuzuki et al.: Study on Non-Energy Benefits of Area-Wide Energy Utilization and Evaluation of the Marginal Abatement Cost, WREC 2011, Linköping

[8] A. Zhivov et al.: Towards a Net-Zero Building Cluster Energy Systems Analysis for the US army Installations, WREC 2011, Linköping

[9] IEA ECBCS Annex 49, H. Erhorn-Kluttig et al.: Retrofitting in Educational Buildings: Energy Concept Adviser for Technical Retrofit Measures, www.ecbcs.org 